Journal of the Egyptian Society of Parasitology, Vol.43, No.3, December 2013 J. Egypt. Soc. Parasitol., 43(3), 2013: 561 - 568

\title{
PREVALENCE OF INTESTINAL PROTOZOAN INFECTIONS AMONG ORANG ASLI SCHOOLCHILDREN IN POS SENDERUT, PAHANG, MALAYSIA
}

\section{By \\ TALAL AL-HARAZI ${ }^{1}$, MOHAMED KAMEL ABD GHANI ${ }^{2}$ And HIDAYATULFATHI OTHMAN ${ }^{2}$}

Department of Medical Parasitology, Faculty of Medicine Taiz University, Yemen ${ }^{1}$ and Department of Biomedical Sciences, Faculty of Allied and Health Sciences, Universiti Kebangsaan Malaysia, Kuala Lumpur, Malaysia $^{2}$ Correspondence: Dr. Talal Al-Harazi, email: alhraziali@yahoo.com

\section{Abstract}

The current study determined the prevalence of intestinal protozoan infections among the Orang Asli schoolchildren in Pos Senderut, Pahang, Malaysia. The overall intestinal protozoan infection rate was $85 \%$ (261 out of 307). The highest prevalence rates were due to Entamoeba coli (24.4\%), Giardia lamblia (21.8\%), Blastocystis hominis (21.2\%) and Entamoeba histolytica (15.0\%). The prevalence of Iodamoeba butschlii was only $2.9 \%$. Among the positive samples, mixed infection with B. hominis and E. histolytica was $3.3 \%, B$. hominis and G. lamblia was $2.9 \%$, G. lamblia and E. histolytica was $2.0 \%$ and triple infections (B. hominis, $G$. lamblia and E. histolytica) was $1.0 \%$. The prevalence of the infection was high in all age groups (6-14 years old). Thus, we can conclude that intestinal protozoan infections are still representing a serious public health problem in aboriginal communities, especially among children.

Keywords Protozoan infections, school children, Orang Asli, Malaysia.

\section{Introduction}

The intestinal parasites are considered as one of the commonest infections worldwide. Approximately 3.5 billion people are affected and 450 million are ill as a result of these infections, the majority being children (Okyay et al, 2004). Numerous protozoa inhabit the gastrointestinal tract of humans; the majority of them are non-pathogenic commensals. The pathogenic protozoa such as Giardia lamblia, Entamoeba histolytica and Blastocystis hominis can cause severe disease under certain conditions such as severe diarrhea. $G$. lamblia and E. histolytica are the most common intestinal protozoa in temperate and tropical countries especially among children (WHO, 2008). Prevalence of blastocystosis in developed countries was varied from $1.5 \%$ to $10 \%$ while in developing countries is varied from 30\% - 50\% (Windsor et al, 2001; 2003). Noor Hayati et al. (1995) in Kuala Lumpur reported 2/196 (1.0\%) duodenal aspirates from immunocompetent patients undergoing endoscopy to have $B$. hominis cysts. Among the 
hospitalized patients the prevalence of blastocystosis was $0.3 \%$ (Noor Hayati et al, 2003). Azian et al. (2007) found that blastocystosis was $52.30 \%$ among aborigines in Pahang. Dhurga et al. (2012) reported that $B$. hominis is one of the commonest protozoan parasite worldwide particularly in Malaysia

In Malaysia, the prevalence of giardiasis was $19.2 \%$ among Malays from rural areas in Trengganu (Noor Hayati et al, 1998a). Also, Noor Hayati et al. (1998b) reported 19.4\% among Orang Asli people in Perak. The prevalence of amoebisais varied from between 1-14\% (Noor Hayati et al, 2003).

In order to update the current status of the intestinal protozoan infections among Orang Asli school children in remote areas in Peninsular Malaysia this study was undertaken in Pos Senderut, Pahang hopping to assist the health policy makers to improve the control measures in order to reduce the prevalence of this infections.

\section{Subjects, Materials and Methods}

This cross-sectional study was carried out among 307 Orang Asli school children aged 6-14 years (156 Males and 151 females) in Pos Senderut, in Pahang, Malaysia in August 2008. The school was selected by the academic staff of Department of Biomedical Science in Faculty of Allied Health Sciences, UKM. The total number of enrolled students in this school is 510 pupils. A list of names of all enrolled students was collected from the headmaster's office. All the children were invited to participate in the study.
Poor socioeconomic status is the predominant feature of this community. Most of the houses were bamboo and with piped water as the source of human consumption, but for domestic needs (bathing, washing clothes, utensils and animals' feeding) was from the rivers located adjacent to the villages without adequate or proper sanitation. Most of the children swim, bath and play in the river, which is the preferred sites for defecation.

The stool specimens were collected in $100 \mathrm{ml}$ labeled screw-cap plastic containers and immediately transported to the laboratory. Samples were concentrated by formalin ethyl acetate sedimentation technique and examined for protozoa as direct wet mount and in Lugol's iodine solution. A child was positive based on cysts and/or trophozoites detection.

Statistical analysis: Data was done using SPSS 13.0. Mean \pm SD were used to present quantitative date where applicable while proportion was used to present qualitative data. Chi-squared test was used to compare prevalence $\mathrm{s}$. $P=0.05$ was considered significant.

Ethical consideration: After a clear explanation for the methodology and objectives the headmaster and children were consented verbally to take part in this study. This study was approved by the Research and Ethics Committee, Faculty of Allied Health Sciences, Universiti Kebangsaan, Malaysia.

\section{Results}

Three hundred and seven Orang Asli schoolchildren participated voluntarily. 
The $\mathrm{M} \pm \mathrm{SD}$ age of the subjects was $10 \pm 1.8$ years. The overall intestinal protozoan infection rate was $85 \%$ (261 out of 307). The prevalence of $G$. lamblia, B. hominis and E. histolytica were $21.8 \%, 21.2 \% \& 15.0 \%$, respectively (Fig. 1). The prevalence of E. coli was $24.4 \%$, and of $I$. butschlii was low $(2.9 \%)$. Prevalence of mixed infection with $B$. hominis and $E$. histolytica was $3.3 \%, B$. hominis and G. lamblia was $2.9 \%$, G. lamblia and E. histolytica was $2.0 \%$ and triple infections (B. hominis, G. lamblia and E. histolytica) was only $1.0 \%$ (Fig. 2). Overall, the infection rate of protozoan was more frequent in females than males but the difference was not statistically significant $\left(\mathrm{X}^{2}=\right.$ $0.886 ; P=0.347)$. The highest infection rate was reported among children aged $6-8$ years $(67.9 \%)$ and $12-14$ years (67.1\%). Females showed higher giardiasis prevalence than males, but without significant $\left(X^{2}=2.792 ; P=0.095\right)$. There was significant difference in the giardiasis prevalence of according to age groups $\left(\mathrm{X}^{2}=6.950 ; P=0.031\right)$. The females had a significantly higher blastocystosis prevalence than males $\left(\mathrm{X}^{2}=5.034 ; P=0.025\right)$. But, there was no significant in the prevalence of $E$. histolytica between males and females.

The details are in tables $\left(\begin{array}{lll}1 & \&\end{array}\right)$ and figures $(1 \& 2)$.

Table 1: Intestinal protozoa among Orang Asli schoolchildren according to sex.

\begin{tabular}{|l|c|c|c|}
\hline Intestinal protozoa & $\begin{array}{c}\text { Male } \\
\mathrm{N}=156(\%)\end{array}$ & $\begin{array}{c}\text { Female } \\
\mathrm{N}=151(\%)\end{array}$ & $\begin{array}{c}\text { Total } \\
\mathrm{N}=307(\%)\end{array}$ \\
\hline G. lamblia & $28(17.9)$ & $39(25.8)$ & $67(21.8)$ \\
\hline E. histolytica & $21(13.5)$ & $24(15.9)$ & $45(14.7)$ \\
\hline B. hominis & $25(16.0)$ & $40(26.5)^{*}$ & $65(21.2)$ \\
\hline E. coli & $37(23.7)$ & $38(25.2)$ & $75(24.4)$ \\
\hline I. butschlii & $5(3.2)$ & $4(2.6)$ & $9(2.9)$ \\
\hline Total & $116(37.8)$ & $145(47.2)$ & $261(85)$ \\
\hline * Significant differen & $(\mathrm{P}<0.05)$ & &
\end{tabular}

* Significant difference $(\mathrm{P}<0.05)$

Table 2: Intestinal protozoa \% among Orang Asli schoolchildren according to age groups

\begin{tabular}{|l|c|c|c|c|c|}
\hline Age group & G. lamblia & E. histolytica & B. hominis & E. coli & I. butschlii \\
\hline $6-8$ & $32.1^{*}$ & 23.5 & 24.7 & 23.5 & 0 \\
\hline $9-11$ & 17.4 & 11.8 & 16.0 & 23.6 & 3.5 \\
\hline $12-14$ & 19.5 & 11.0 & 26.8 & 26.8 & 4.9 \\
\hline Total & 21.8 & 14.7 & 21.2 & 24.4 & 2.9 \\
\hline
\end{tabular}

* Significant difference $(\mathrm{P}<0.05$

\section{Discussion}

The intestinal protozoa are widely distributed around the world, and infections usually vary according to immunity, region and age. An increase in the incidence of these infections is evident in low socio-economic communities with poor sanitation (Dinleyici et al,
2003). G. duodenalis, E. histolytica and $B$. hominis infections are endemic in most tropical and subtropical countries. G. duodenalis is a well-known predictor of impaired growth of children in rural areas of developing countries (Gendrel et al, 2003; Al-Mekhlafi et al, 2005). E. histolytica was respon- 
sible for millions of cases of dysentery and liver abscess each year (WHO, 1997). Epidemiological studies in different countries showed that socioeconomic situation has an important role in the prevalence of intestinal protozoa.

The poor sanitary and environmental conditions are relevant in the propagations of these infectious agents (Tellez et al, 1997; Phiri et al, 2000).

The prevalence of intestinal parasites in Malaysia is common especially among aborigines who live in remote areas near rivers or streams water which contaminated with ova or cyst passed out with feces to the water (Noor Hayati et al, 2003). This current study reported a high prevalence (85\%) of $G$. lamblia $(21.8 \%)$, B. hominis (21.2\%), E. histolytica (15\%) and $I$. butschlii $(2.9 \%)$ and this indicates a high exposure of these children to protozoan infections. This result agreed with previous studies conducted in other states in Malaysia (Noor Hayati et al., 1998; Al-Mekhlafi et al, 2005; Mahdy et al, 2008). But, Noor Azian et al. (2007) in Pahang among 130 individuals $94(72.3 \%)$ were positive with at least one intestinal protozoa. These were B. hominis, G. lamblia, E. histolytica, E. coli, E. hartmani, E. polecki, Endolimax nana, I. butschlii and Chilomastix mesnili were detected. $B$. hominis were (52.3\%), followed by $G$. lamblia $(29.2 \%)$, E. coli $(26.2 \%)$ and E. histolytica $(18.5 \%)$. Mixed infection with E. histolytica and G. lamblia was $3.8 \%$, E. histolytica and B. hominis was $15.4 \%$, G. lamblia and B. hominis was $17.7 \%$. Triple infection of $E$. histolyti$c a, G$. lamblia and B. hominis was
$3.1 \%$. Infection was more prevalent in children below 10 years $(45.4 \%)$ and lowest in ages above 60 years $(3.8 \%)$. The present prevalence of blastocystosis was much higher than previous studies and this could be due to the exposure to sources of infections in the Orang Asli's communities. Suresh et al. (2005) found that Blastocystis cysts in 47/123 of sewage treatment workers (37 Scottish, 17 Malaysian). Vennilla et al. (1999) found blastocystosis (5.6\%) among symptomatic patients in Kuala Lumpur, Malaysia. In comparison with other countries, Suresh and Smith (2004) found that almost $4.0 \%$ of patients with gastrointestinal symptoms from Scotland were infected with $B$. hominis and $20.5 \%$ of the cases excreted cysts.

Water-borne parasites are the most frequent mechanism of spread and person-to-person transmission can occur (Adarosy et al, 2013). Water supply is an important risk factor for borne parasitosis from municipal water supplies contaminated with human waste (Enander et al, 2012). Contamination of drinking water with Giardia has been increasingly recognized over the past 10 years as a cause of water-borne diseases in humans (Xiao et al, 2013). Furthermore, Cryptosporidium oocysts and $G$. lamblia cysts were found in water sources (El Shazly et al, 2007) and even in $10 \%$ of samples of swimming pools (Abd El-Salam, 2012). Practicing good hygiene (e.g., wash hands with soap and water before eating) and avoiding using contaminated water/food are the main preventive measures to prevent common intestinal 
protozoa (Alum et al, 2010).

The present study found no significant differences in protozoan infections between sexes and this could be due to the similar daily routine chores of both of them. This agreed with Nimri (1994) in Jordan, Okyay et al. (2004) in Turkey, Kassem et al. (2007) in Libya, Fathy (2011) in Egypt, and Mohammad and Koshak (2011) in Saudi Arabia. In contrast, $B$. hominis was significantly higher in males than females. In present study, all age groups were infected by one or more protozoa. This result agreed with previous studies in Malaysia (Al-Mekhlafi et al, 2005). Giardiasis was more prevalent among young children aged 6-8 years, which agreed with Noor Hayati et al. (1998). The younger age group was shown to be at higher risk to be infected with intestinal protozoa than the older age group; this could be due to the lake of health education among mothers in looking after their children. This could be also due to immune-modulating factors as the immunity of young children is lower than the older children.

During the study visits the personal hygiene of aborigine population in this community was very poor. Children tend to have peculiar habits such as playing outside barefooted and not washing hands before and after eating, and consumes raw fruits and sugar cane without washing. Beside these factors, lack of proper sanitation has an important role in the transmission of protozoan infections in the community.

\section{Conclusion}

The outcome results emphasized that intestinal protozoan infections are still a major public health challenge that needs to be addressed to decrease its burden on the health care system and the welfare. The high prevalence was attributable to poor environmental management, poor personal hygiene and lack of health education. The public education, health promotion, improving sanitation conditions of underdeveloped areas/communities, community involvement and supporting evidence-based practice/programs are the keys to success in preventing the spread of intestinal protozoan infections in Malaysia. In this regard, the present findings are a basis to develop strategies and preventive programs targeting groups at greater risk of intestinal protozoan infections.

\section{Acknowledgments}

The authors would like to thank Dr. Hesham Al-Mekhlafi from University of Malaya for his generous help.

Thanks are also due to Ebtesam AlAsbahi and Dr. Sami Abdo Radman from Universiti Kebangsaan Malaysia for their fruitful help in data analysis.

\section{References}

Abd El-Salam, MM, 2012: Assessment of water quality of some swimming pools: a case study in Alexandria, Egypt. Environ. Monit. Assess. 184, 12:7395-406

Adarosy, HA, Gad, YZ, El-Baz, SA, El-Shazly, AM, 2013: Changing pattern of fascioliasis prevalence early in the 3rd millennium in Dakahlia Governorate, Egypt: an update. J. Egypt. Soc. Parasitol. 43, 1:275-86.

Al-Mekhlafi, HMS, Azlin, M, Noor 
Aini, U, Shaik, A, Sa'iah, A, et al, 2005: Giardiasis is a predictor of childhood malnutrition in Orang Asli children in Malaysia. Trans R. Soc. Trop. Med. Hyg. 99, 9:686-91.

Alum, A, Rubino, JR, Ijaz, MK, 2010: The global war against intestinal para-sites-should we use a holistic approach? Int. J. Infect. Dis. 14, 9:e732-8

Dhurga, DB, Suresh, KG, Tan, TC, Chandramathi, S, 2012: Apoptosis in Blastocystis spp. is related to subtype. Trans. R. Soc. Trop. Med. Hyg. 106, 12:725-30.

Dinleyici, EC, Dogan, N, Ucar, B, Ilhan, H, 2003: Strongyloidiasis associated with amebiasis and giardiaisis in an immunocompetent boy presented with acute abdomen. Korean J. Parasitol. 41, 4:239-42.

El Shazly, AM, Elsheikha, HM, Soltan, DM, Mohammad, KA, Morsy, T A, 2007: Protozoal pollution of surface water sources in Dakahlia Governorate, Egypt. J. Egypt. Soc. Parasitol. 37, 1: 51-64.

Enander, RT, Hanumara, RC, Kobayashi, H, Gagnon, RN, Park, E, et al, 2012: Reducing drinking water supply chemical contamination: risks from underground storage tanks. Risk Anal. 32, 12:2182-97

Fathy, FM, 2011: A study on Blastocystis hominis in food-handlers: diagnosis and potential pathogenicity. J. Egypt. Soc. Parasitol. 41, 2:433-53.

Gendrel, D, Treluyer, JM, RichardLenoble, D, 2003: Parasitic diarrhea in normal and malnourished children. Fund. Clin. Pharmacol. 17, 2:189-98.

Kassem, HH, Zaed, HA, Sadaga, GA
2007: Intestinal parasitic infection among children and neonatus admitted to Ibn-Sina Hospital, Sirt, Libya. J. Egypt. Soc. Parasitol. 37, 2:371-80.

Mahdy, MAK, Lim, YAL, Surin, J, Wan, KL, Al-Mekhlafi, HMS, 2008: Risk factors for endemic giardiasishighlighting the association of contaminated water and food. Trans. R. Soc. Trop. Med. Hyg. 102, 5:465-70.

Mohammad, KA, Koshak, EA, 2011: A prospective study on parasites among expatriate workers in Al-Baha from 2009-2011, Saudi Arabia. J. Egypt. Soc. Parasitol. 41, 2:423-32.

Nimri, LF, 1994: Prevalence of giardiasis among primary school children. Child Care Hlth. Dev. 20, 4:231-7.

Noor Azian, MY, San, YM, Gan, CC, Yusri, MY, Nurulsyamzawaty, Y, et al. 2007: Prevalence of intestinal protozoa in an aborigine community in Pahang, Malaysia. Trop. Biomed. 24, 1: 55-62.

Noor Hayati, M, Fatmah, MS, Yusof, S, 2003: Intestinal parasitic infections in man: A review. Med. J. Malay 58:210.

Noor Hayati, MI, Oothuman, P, Fatmah, MS, Zainudin, B, et al, 1995: Nutrient intake and socio-economic status among the children attending a health exhibition in Malaysian rural villages. Med. J. Malay 50, 4:382-90.

Noor Hayati, M, Fatmah, MS, Yusof, S, Edariah, AB, 1998a: Intestinal parasitic infections in man: a review. Med. J. Malay 58:296-305.

Noor Hayati, MI, Sano, MI, Mohammed, CG, Norhayati, M, Rohani, A K, et al, 1998b: Infeksi parasitusus pa- 
da maysarakat Orang Asli si Pos Piah, Sungei Siput (U), Perak. Proceed. $2^{\text {nd }}$ National Health Science Symposium.

Okyay, P, Ertug, S, Gultekin, B, Omewn, O, Beser, E, 2004: Intestinal parasites prevalence and related factors in school children, a western city sample, Turkey Pub. Hlth. 4:64-8.

Phiri, K, Whitty, CJ, Graham, SM, Ssembatya-Lule, G, 2000: Urban/rural differences in prevalence and risk factors for intestinal helminth infection in southern Malawi. Ann. Trop. Med. Parasitol. 94, 4:381-7.

Rajeswary, B, Sinniah, B, Hasnah, H, 1994: Socio-economic factors associated with intestinal parasite among children living in Gombak, Malaysia. Asia Pac. J. Pub. Hlth,. 7: 21-5.

Shaw, PK, Brodsky, RE, Lyman, D O, Wood, BT, Hibler, CP, et al, 1997: A community wide outbreak of giardiasis with evidence of transmission by a municipal water supply. Ann. Int.Med. 87:426-32.

Suresh, K,. Smith, HV, 2004: Comparison of methods for detecting Blastocystis hominis. Eur. J. Clin. Infect. Dis. 23:509-11.

Suresh, K, Smith, HV, Tan, TC, 2005: Viable Blastocystis cysts in
Scottish and Malaysian sewage samples. Appl. Environ. Microbiol. 71, 9: 5619-20.

Tellez, A, Morales, W, Rivera, T, Meyer, E, Leiva, B, et al, 1997: Prevalence of intestinal parasites in the population of Leon, Nicaragua. Acta Trop. 66:119-25.

Vennilla, GD, Suresh, K, Salim, HS, Anuar, AK, Kudva, M, et al, 1999: Diarrhea in patients infected with Blastocystis hominis. Int. Med. Res. J. 3:335.

WHO, 1997: Amoebiasis: Weekly Epidemiology Record. 72:97-9, Geneva.

WHO, 2008: The Global Burden of Disease: 2004 update. Geneva.

Windsor, JJ, Macfarlane, L, Whiteside, TM, 2003: Blastocystis hominis. Am. J. Trop. Med. Hyg. 69:213-8.

Windsor, JJ, Macfarlane, L, Whiteside, TM, Chalmers. RM, Thomas, AL, et al, 2001: Blastocystis hominis: a common yet neglected human parasite. Brit. J. Biomed. Sci. 58, 2:129-30.

Xiao, G, Qiu, Z, Qi, J, Chen, JA, Liu, F, et al, 2013: Occurrence and potential health risk of Cryptosporidium and Giardia in the three Gorges Reservoir in China. Water Res. 47, 7:2431-45. 




Figure 1: Prevalence of intestinal protozoan infections among Orang Asli schoolchildren

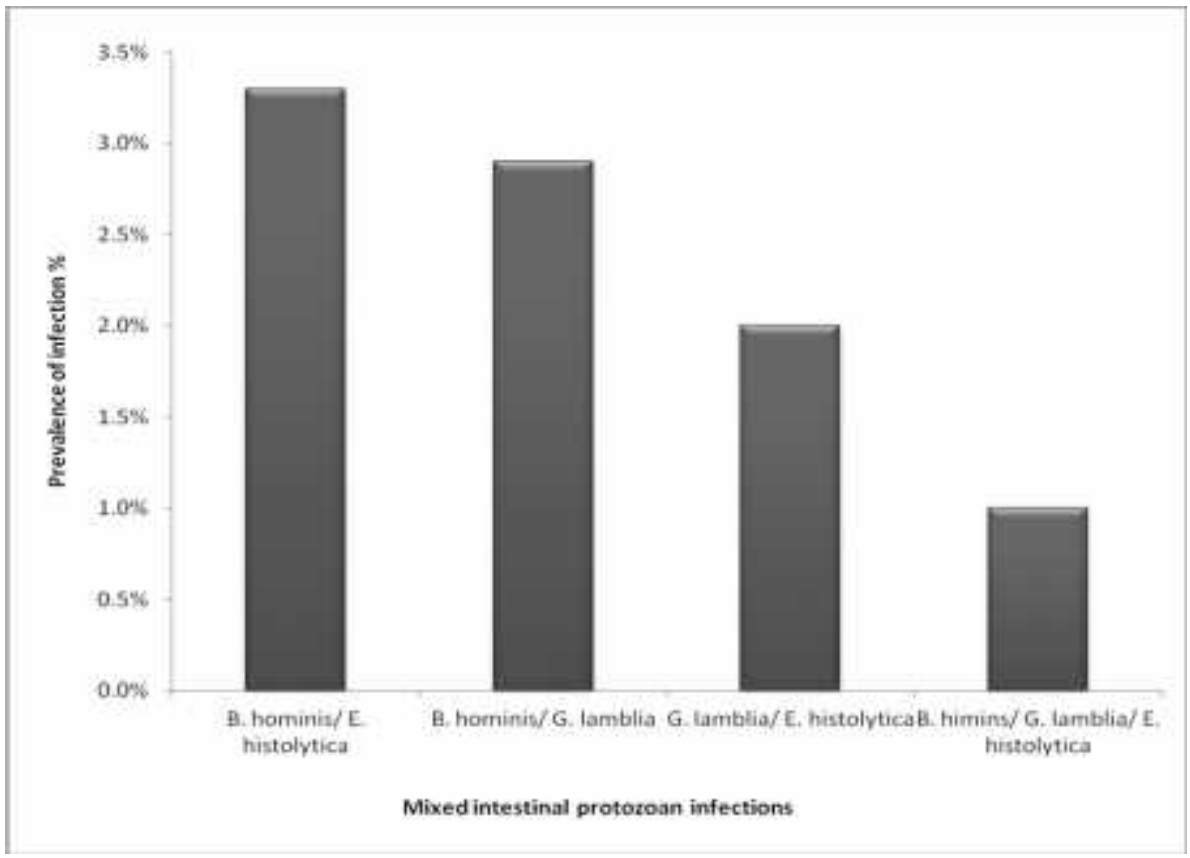

Figure 2: Prevalence of mixed intestinal protozoan infections among Orang Asli schoolchildren 